\title{
Socializando o pesquisador a observar a socialização dos sujeitos: notas sobre pesquisas com as elites
}

\author{
Socializing the researcher to observe the socialization of the subjects: \\ notes on research with the elites
}

\section{Socializar al investigador para observar la socialización de los sujetos: apuntes sobre la investigación con las élites}

\author{
Maria da Graça Jacintho Setton* \\ Ce point devrait là aussi faire objet d'une réflexion collective \\ interrogeant la capacité d'une profession à produire un \\ point de vue sur le fonctionnement des élites qui ne soit \\ tributaire ni d'une revanche de classe, ni d'une forme \\ d'admiration, ni même enfin d'un tropisme scolastique'.
}

\section{Resumo}

O objetivo deste artigo é apresentar informações preliminares acerca da pesquisa intitulada Pensamento e práticas culturais da elite paulistana ${ }^{2}$. A intenção é problematizar e circunstanciar questões de ordem metodológica e teórica observadas no decorrer do trabalho de investigação. Mais especificamente, serão expostas as dificuldades e as estratégias utilizadas para contornar as difíceis relações com um grupo social seleto - as elites da sociedade paulistana. Articuladas a esta questão, serão analisadas algumas impressões das frações estudadas, suas idiossincrasias a partir do pertencimento neste grupo e setores da economia que representam. Trata-se de uma primeira explanação de dados mais gerais da pesquisa, que busca compreender as formas de justificação da dominação e as representações sociais das elites a partir de suas trajetórias sociais, tendo como perspectiva teórica a sociologia da socialização.

Palavras-chave: socialização; elites; desigualdade social; camadas sociais.

Recebido em: 30/07/2020 - Aprovado em: 13/01/2021

http://dx.doi.org/10.5335/rep.v28i1.12972

Graduada e mestra em Ciências Sociais pela PUC-SP e doutora em Sociologia pela USP. Professora Titular em Sociologia da Educação na Faculdade de Educação da USP. Livre-Docente em Sociologia da Educação na Faculdade de Educação da USP. Entre 2010 e 2013, coordenou o GT 14 - Sociologia da Educação da Anped. Coordena o GPS - Grupo Práticas de Socialização Contemporâneas, desde 2003. Tem pós-doutorado pela USP (1997) e pela EHESS - Paris (2000) e na Unicamp (2012-2013). Em 2008, atuou como professora convidada no Groupe de Recherche sur la Socialisation, na Université Lumière 2, em Lyon, França, e na Universidade de Coimbra, Portugal. Em 2012, participou de um estágio de pesquisa na Université Paris-Descartes, Sorbonne, em Sciences Humaines et Sociales. Orcid: http://orcid. org/0000-0001-7306-9293. E-mail: gracaset@usp.br 


\section{Abstract}

The purpose of this article is to present preliminary information about the research entitled Thought and Cultural Practices of Elite Paulistana. The intention is to problematize issues of methodological and theoretical order observed during the research work. More specifically, the difficulties and strategies used to overcome the difficult relationships with a select social group - the elites of São Paulo society. Linked to this issue, some impressions of the fractions studied will be analyzed, their idiosyncrasies based on belonging to this group and the sectors of the economy they represent. It is a first explanation of more general data from the research that seeks to understand the forms of justification of domination and the social representations of elites from their social trajectories with the sociology of socialization as a theoretical perspective.

Keywords: socialization; elites; social inequality; social strata.

\section{Resumen}

El propósito de este artículo es presentar información preliminar sobre la investigación titulada Pensamiento y prácticas culturales de la élite Paulistana. La intención es problematizar cuestiones coyunturales de orden metodológico y teórico observadas durante el trabajo de investigación. Más específicamente, se expondrán las dificultades y estrategias utilizadas para sortear las difíciles relaciones con un grupo social selecto, las élites de la sociedad paulista. Vinculado a este tema, se analizarán algunas impresiones de las fracciones estudiadas, sus idiosincrasias en función de la pertenencia a este grupo y los sectores de la economía que representan. Es una primera explicación de datos de investigación más generales que busca comprender las formas de justificación de la dominación y las representaciones sociales de las élites desde sus trayectorias sociales con la sociología de la socialización como perspectiva teórica.

Palabras clave: socialización; élites; desigualdad social; capas sociales.

\section{Introdução}

A epígrafe alerta a pesquisadora e a todos que estudam empiricamente as frações privilegiadas. Trata-se de um desafio constante em investigações que refletem as concepções de mundo das elites e suas representações políticas em sociedades tão desiguais.

Desde o início, antes mesmo de formalizar a proposta da pesquisa em tela, desenvolveu-se um anseio de que, devido a algumas relações, tinha-se o compromisso de desvelar os modos de justificação da dominação das elites, suas interpretações sobre as desigualdades sociais e responsabilidades em relação a este estado social. Convivendo e circulando em um grupo em que muitos agentes se destacavam por um protagonismo em suas áreas de atuação, estava convencida de que um ou dois contatos fariam com que se chegasse a estes sujeitos tão pouco acessíveis a uma boa parcela de pesquisadores das ciências sociais.

A intenção era obter mais informações sobre este grupo raramente estudado até então. Em aulas e palestras nas universidades, eram sempre frequentes a impressão 
de que, ao apresentar a obra de Pierre Bourdieu, tinha acumulado mais conhecimentos sobre as camadas médias e populares do que sobre as elites brasileiras. Tal percepção sucessivamente esteve presente pois fazendo uso de uma sociologia relacional, ou seja, partindo de uma leitura em que se compreende as relações de aproximação e ou de distanciamento entre os grupos através do jogo simbólico das distinções sociais, apresentou-se forçoso a imposição de um novo objeto de pesquisa (BOURDIEU, [1979]2007). Como se reproduzem os grupos de elite? Como estes setores privilegiados reproduzem e justificam a dominação? Quais as estratégias de dominação que fazem uso? Qual a leitura que fazem sobre a desigualdade social em nosso país?3

Ainda que o escopo da investigação em questão seja maior, neste artigo só irão ser discutidos três aspectos: o tipo de pertencimento a frações das elites, os setores da economia a que estão relacionados e suas justificativas acerca da desigualdade social no Brasil a partir da teoria da socialização. ${ }^{4}$ Concordando com Berthelot (1983), as teorias da socialização compreendem um conjunto de investigações que possuem foco nas instituições, nos valores, na história e na vida dos indivíduos. Uma perspectiva capaz de associar, simultaneamente, quatro elementos essenciais para a análise de qualquer fenômeno social. Dessa maneira, tais teorias, ainda que não perceptível a todos, possui potencial analítico singular, na medida em que serve para interpretar aspectos da reprodução social, a origem social dos grupos e suas representações em várias dimensões socioculturais (SETTON; BOZZETTO, 2020).

Dando encaminhamento a esta ordem de questões, propus uma investigação sobre nove setores representativos das elites. Embora tenha como pressuposto de que as elites se compõem de muitas frações (KHAN, 2012), inicialmente investigou-se os seguintes domínios: a) políticos/ex-ministros/assessores; b) celebridades intelectuais; c) empresários da agricultura/pecuária; d) empresários do comércio; e) empresários industriais; f) empresários das finanças; g) profissionais liberais; $h$ ) empresários da comunicação; i) altos executivos. ${ }^{5}$

Durante praticamente dois anos, teceu-se uma rede de relações, solicitações e agradecimentos de porte razoável. Para chegar aos 48 sujeitos entrevistados foi necessário falar com mais de uma centena de pessoas. A ideia inicial de que um entrevistado poderia apresentar a mais um não se realizou. Sempre muito cuidadosos, raras as vezes um ou outro se dispôs a indicar um possível contato. Nem sempre havia clima para fazer esta solicitação. De contínuo muito ocupados, com tempo contado no relógio, sempre se privilegiou a condução do encontro a fim de dar conta de tudo que estava contemplado no roteiro da investigação. Vale destacar que houve exceções. Nas últimas entrevistas, no final de 2019, já tentando fechar 
o quadro de sujeitos participantes, um grupo de mulheres contatadas auxiliou na relação com outras empresárias.

$\mathrm{Na}$ maioria das vezes, conseguia-se o telefone celular do possível entrevistado/a e fazia o contato pelo WhatsApp. Em outras ocasiões, contatava-se secretárias e por último o recurso do e-mail. As respostas nunca foram imediatas. De dois a cinco dias para obter algum tipo de resposta. Alguns deles ainda se espera retorno. De maneira cuidadosa iam sendo feitas cobranças ou lembretes de comprometimentos já anunciados. A intenção em realizar as entrevistas em um semestre, tornou-se absolutamente imprópria. Imaginou-se também que a etapa da pesquisa de entrevistas iria finalizar-se em novembro de 2018. Contudo, em função das dificuldades encontradas no decorrer dos agendamentos alguns sujeitos só foram abordados no decorrer do ano de 2019. Como foi verificado, o acesso a este grupo é um processo moroso, exige paciência e determinação (GENÉ, 2014; LAURENS, 2007; PINÇON; PINÇON-CHARLOT, 1989, 2007). Tudo leva a crer que o período e o clima tenso das eleições para cargos do executivo e legislativo de 2018 dificultou os encontros. Isso porque alguns setores estavam bastante envolvidos com a discussão da pauta dos candidatos como os políticos e os profissionais da comunicação.

Os setores em que os contatos foram mais fáceis foram as celebridades intelectuais, os profissionais das finanças e sobretudo as mulheres empresárias. Altos executivos foi um setor que a própria leitura teórica impôs dado que a bibliografia aborda tais personalidades como uma das responsáveis pela manutenção de uma ordem social e econômica. Eles também foram bem acessíveis. Mesmo não sendo proprietários de grandes empresas, eram e são com frequência detentores de muita influência em seus âmbitos de trabalho.

É notável a coincidência de localização dos escritórios ou residências dos entrevistados. Um ou outro se destacou por sair do circuito Vila Nova Conceição, Itaim-Bibi e Jardins, bairros nobres e de ricas construções imobiliárias da cidade. Vale ressaltar uma curiosidade - a denominação dos prédios em que muitos possuíam escritórios. Central Park, Tower Pinheiros, Metropolitan, entre outros, são exemplos de nomes dos imóveis numa conexão explícita com negócios no exterior.

O tempo necessário para o trajeto e a realização de cada encontro não era menor do que quatro horas. Um deslocamento de ida e volta de aproximadamente uma hora e meia e mais o próprio tempo da entrevista, no mínimo 50 minutos e no máximo duas horas, comprometiam toda uma manhã ou mesmo uma tarde inteira. Poucas entrevistas se realizaram na residência dos sujeitos, apenas 10 de um total de 48 . Tudo leva a crer que, na tentativa de agilizar a solicitação, grande parte dos conta- 
tados agendava o encontro para os momentos livres em seus escritórios. A espera no lado de fora na recepção ou em salas de reunião ou mesmo a expectativa de atraso da pesquisadora sempre faziam emergir certa tensão a cada encontro. A procura de estacionamentos em ruas movimentadas e a consulta de que não havia sido esquecido nenhum item para a realização do encontro mobilizavam uma atenção constante. O maior tempo de espera foi de três horas, mas isto não se deu de forma constante. A grande maioria respeitou os horários. De duração de aproximadamente uma hora, as entrevistas variaram de 3 horas a 40 minutos. Uma parcela reduzida tinha curiosidade sobre o destino das informações. Um dado de pesquisa parece importante ser declarado. Nunca chegar atrasada. Nas ocasiões em que os encontros se davam na residência do entrevistado, procurou-se ser o mais pontual possível. Nas entrevistas em sede das empresas, a chegada com alguns minutos de antecedência sempre foi importante, dado que a apresentação de credenciais e a passagem por muitos mediadores (porteiros, secretárias, espera de elevadores) exigiam uma folga de tempo.

$O$ roteiro de entrevista foi se modificando ao longo da pesquisa. Algumas questões foram deslocadas da ordem inicial e outras foram suprimidas devido a uma confusão de entendimento feita pelos entrevistados, o que alongava as explicações. ${ }^{6}$ $\mathrm{Na}$ verdade, não fizeram falta, pois, no transcorrer dos encontros, as respostas eram dadas de maneira espontânea.

Definida inicialmente a partir de um corte setorial, a investigação tinha como preocupação realizar um corte geracional (32 a 40; 41 a 50; 51 a 65; mais de 66 anos) e um corte de gênero. ${ }^{7}$ No entanto, uma certa margem de flexibilidade foi necessária. Isto é, foi difícil encontrar sujeitos do sexo masculino ou feminino com sucesso profissional com menos de 40 anos. Grande parte deles começam a se destacar no meio empresarial a partir de 50 anos ou mais. É possível afirmar ainda que o sexo feminino se mostrou mais evidente em alguns setores, como finanças, comunicação, profissionais liberais e altos executivos, do que em outros, como indústria, comércio e política. Pelo menos, em cada um dos setores investigados, procurou-se um sujeito que se destacasse dos demais devido a uma herança invejável e ou mesmo uma trajetória de sucesso que o alçou a um posto cobiçado de muita influência e poder. Foram entrevistados 25 homens e 23 mulheres.

\section{Primeiras impressões}

Ter as elites como objeto e ou sujeito de pesquisa é um assunto absorvente. Como não se deixar levar pela proximidade entre o entrevistador e o entrevistado, 
como objetivar o objeto impondo um estranhamento necessário e cientificamente seguro? Incorporar uma vigilância epistemológica é estar em constante autoavaliação na procura de uma permanente autocrítica ao se deparar com sujeitos de pesquisa que convivem, são coniventes e eventualmente se importam com as desigualdades sociais brutais do Brasil. Fenômeno multidimensional, a desigualdade não se esgota nas diferenças de renda, mas nas diferenças de oportunidade, escolaridade, moradia e saúde, que por certo encerram uma subjetividade eivada de dificuldades e marcada por um futuro desqualificado de difícil retorno (THERBORN, 2001).

Como diria Bourdieu, em seu conhecido jogo de palavras, entende-se objetivação participante como uma objetivação do sujeito da objetivação, objetivação do próprio pesquisador analisando ele mesmo, aquele que deve observar observando a observar o observador no seu trabalho de observação ou de transcrição das observações no e por um retorno sobre sua experiência de campo. ${ }^{8}$

O fato de ser apresentada como professora titular da Universidade de São Paulo abriu muitas portas e uma certa proximidade entre pesquisadora e pesquisado já se estabelecia facilitando o desenrolar da conversa. Em tom despretensioso e informal as entrevistas foram conduzidas com tranquilidade. No final de cada uma delas observou-se certa descontração entre os sujeitos já que as questões não versavam sobre dados financeiros e sim sociais e culturais. Cada encontro e cada entrevista foram comemorados com entusiasmo. Tendo feito uma breve pesquisa sobre cada investigado, acabou-se por construir certa convivência com eles mesmo antes dos encontros. Na tentativa de criar um ambiente de empatia, logo no início, estabelecia-se certa informalidade chamando-os pelos nomes, sem nenhum título de senhor, senhora, doutor ou doutora. Poucas foram as ocasiões em que isso não ocorreu.

Por fim, ao apresentar a pesquisa, nunca foi usada a palavra elite. Sempre se apresentaram as razões do contato como um estudo de natureza acadêmica, no campo da sociologia da educação, sobre a trajetória social e profissional de indivíduos que possuíam uma posição de destaque em sua área de formação. A preocupação era de que a palavra elite poderia despertar certa conotação negativa podendo, em certos casos, embaraçar os sujeitos entrevistados.

\section{Como apresentar os participantes}

A amostra não representativa de 48 participantes foi constituída de personalidades de nove setores econômicos. É possível afirmar que entre eles revelou-se um corpo expressivo de individualidades notáveis que compõem o leque variado e 
diversificado das frações da elite paulistana. No campo dos 1) profissionais liberais contamos com a presença de três homens e uma mulher, sócios-proprietários de escritórios de advocacia de expressão nacional e internacional. No âmbito dos 2) alto-executivos tivemos a participação de dois homens, um deles homossexual e duas mulheres vinculados a multinacionais de duas indústrias farmacêuticas, uma instituição financeira norte-americana, uma empresa multinacional de consultoria de gestão e pesquisa de executivos e uma instituição patronal do setor industrial.

$\mathrm{Na}$ esfera do 3) comércio e serviços, fizemos contato com três mulheres e dois homens, proprietários de empresas de grande porte, entre elas distribuidoras de doces, remédios/ cosméticos, material de papelaria e editora de livros. Por outro lado, tivemos a participação de uma proprietária/produtora de bens de luxo, uma das herdeiras de um complexo fabril gigantesco. No domínio da 4) indústria, contou-se com três proprietários e um ex-proprietário de empresas de médio e grande porte do setor têxtil, siderúrgico, automobilístico e de bebidas. Três homens e quatro mulheres. No setor das 5) finanças, a participação de duas mulheres e dois homens representaram a seção de empresas brasileiras de gestão de recursos familiares patrimoniais. Entre os homens destacam-se um ex-banqueiro e um dos maiores colecionadores de arte no Brasil.

No campo das 6) comunicações, tivemos a presença de oito representantes. Duas proprietárias de empreendimentos publicitários responsáveis por contas de grandes empresas nacionais e internacionais. Ainda no campo da difusão cultural quatro homens e uma mulher na função de cronistas, articulistas e editores dos maiores veículos jornalísticos do Brasil. Dois deles responsáveis pela introdução de inovações neste setor nos anos 1980 e 2000 sendo ambos proprietários de editoras e ou revistas. Por último, salienta-se a presença de uma das herdeiras do maior complexo editorial do país. No âmbito da 7) política, observa-se uma maior diversificação. Dois deputados federais, dois ex-ministros de Estado, um ex-senador da República, que passou experiências como deputado e vereador, e a única mulher, uma das herdeiras de uma das maiores fortunas do Brasil. No setor das 8) celebridades, buscamos uma variedade de personalidades na área da cultura e comportamento. Aqui se apresentam três mulheres de atividades bem distintas. Uma voltada para a área de bem-estar comportamental e a outra atuando no mundo das belas artes como colecionadora e patrona de museus e a última a maior ícone de tendências e moda no país. Entre os homens, destaca-se um colunista, intelectual, que escreve crônicas sobre o Brasil contemporâneo. 
Por último, no 9) agronegócio, destacam-se homens e mulheres proprietários de grandes extensões de terra e gado, ganhadores de prêmios no mundo da pecuária e herdeiros que garantiram um enorme sucesso econômico em investimentos no cultivo da cana. Aqui se destacam dois homens, duas mulheres e uma homossexual.

\section{0 pertencimento às elites}

No que se refere às formas de pertencimento às elites foi possível classificar as frações estudadas em quatro grupos. O primeiro deles se refere ao grupo mais antigo, onde os pesquisados estão há três gerações nesta posição. Ou seja, seus pais e avós já pertenciam às frações das elites. São herdeiros/as do mercado financeiro, da indústria, do comércio ou vieram das frações de políticos como governadores e secretários de Estado.

Os indivíduos que se destacam por estarem há duas gerações na elite herdaram um ambiente familiar escolarizado e estão no segundo grupo. Hoje dedicando-se à indústria, ao comércio, ao agronegócio são na maioria imigrantes em uma segunda ou terceira geração que herdaram de seus pais e avós uma expertise técnica, não universitária, que se fez relevante em uma época de crescimento econômico no Brasil dos anos 1930 a 1940 . Na grande parte das vezes trazendo em suas bagagens apenas a boa vontade, seus familiares contaram com o auxílio da família para consolidar os empreendimentos.

O terceiro agrupamento se sobressai por ter uma representação expressiva, caracterizado por uma herança de capital cultural distintivo no período dos anos 1950 e 1960 e, anterior a ele, bem como uma alta escolarização no Brasil e no exterior. São indivíduos provenientes de famílias intelectualizadas. Isto é, tinham avós ou pais possuidores de nível superior quando este nível de escolarização ainda era privilégio de muito poucos no Brasil. Imigrantes, conhecedores de idiomas (alemão, italiano, espanhol, árabe e francês) e de formação em áreas variadas do conhecimento passaram a fazer parte da convivência de frações economicamente mais abastadas o que os colocou em uma situação relacional privilegiada. Este grupo que se notabiliza no campo cultural, hoje são intelectuais, jornalistas, colecionadores de arte, consultores das finanças, ainda que assegurem para si um confortável estilo de vida.

Por fim, o quarto grupo chama atenção também pela expressão numérica. Os sujeitos pesquisados aqui se destacam em função do tipo de conhecimento e ou capital cultural que acumularam por eles mesmos. Poderíamos denominá-los de 
altamente escolarizados provenientes de frações do comércio, profissionais liberais numa segunda geração de imigrantes, cujos pais e avós ainda não possuíam nível universitário, ou se o tinham, não foi suficiente para alcançar os grupos de elite. Conhecedores de idiomas como o francês e o alemão usufruíram de um capital internacionalizado já logo cedo se identificando com as novidades empresariais mundializadas. Ainda no campo da distinção relativa a uma escolarização nota-se a presença de sujeitos que se fizeram individualmente por estarem up-to-date com as tecnologias e souberam se relacionar com grupos dominantes a fim de se alocarem em cargos de poder ou mesmo na condução de empresas em que uma expertise se fazia necessária no campo empresarial nos anos de 1990.

Para os interesses desta discussão, vale destacar que a classificação de tipo de pertencimento às elites retoma em vários aspectos as teorias da socialização. Indivíduos há mais tempo nos ambientes privilegiados tecem subjetividades, relações e disposições de habitus diferenciadas de outras frações das elites (BOURDIEU, [1979]2007). Em artigo anterior, foi possível observar quatro elementos que são recorrentes em processos socializadores destes grupos; espaço, tempo, laços e internacionalização (SETTON, 2020). Nos grupos mais antigos, verifica-se a presença marcante dos dois primeiros aspectos - espaço e tempo - o que lhes garantiu certa segurança de status, uma subjetividade marcada pela superioridade, um sentimento de comparação aos outros que lhes confere uma diferenciação real. Ou seja, são aqueles indivíduos que estão longe das necessidades da sobrevivência, que têm as vidas marcadas por planos de escolarização longeva e oportunidades de emprego garantidas por herança ou um capital de relações. Todas situações balizadas por condições de socialização estabelecidas $a$ priori.

Por outro lado, as frações intelectualizadas e escolarizadas revelam processos de socialização condicionadas por laços, interações sociais, afinidades no matrimônio e oportunidades de trabalho permeadas por uma história social internacionalizada. São imigrantes, conhecedores de expertises e tecnologias ainda novas no Brasil na ocasião da chegada de suas famílias em solo nacional. Experiências socializadoras precedidas de muito esforço, uma ambiência cultural propícia em que se valoriza um capital cultural profissional, técnico e informatizado. Por certo, todos os elementos acima mencionados fazem parte de uma configuração social complexa em que a interdependência de todos eles tecem trajetórias diferenciadas ainda que cada um dos elementos possa ter um destaque (ELIAS, 1999). 


\section{As desigualdades sociais no Brasil}

Seguindo certa inspiração sobre o tema em tela, as leituras de artigos, como os escritos em 1997 por Elisa Reis, em 2000 por Celi Scalon e em 2015 por Graziela Moraes Silva e Matias López, motivaram a incorporação de questões relativas ao entendimento das elites sobre os problemas de natureza social no Brasil. Segundo estes estudiosos, ainda que um grupo de pesquisadores tenha se debruçado sobre aspectos da desigualdade na sua dimensão econômica, poucos ainda se dedicaram a se aprofundar nas representações das elites sobre a dinâmica das diferenças e ou distinções entre as camadas sociais e seus efeitos culturais. É interessante notar o espaçamento de tempo entre as publicações acima. Com amostras bastante diferenciadas entre si é notável, contudo, a convergência dos procedimentos e respostas.

$\mathrm{O}$ artigo de Reis (2000) que trabalha com base em uma pesquisa nacional e internacional, consulta um conjunto de sujeitos pertencentes às elites. ${ }^{9}$ Políticos, burocratas, líderes sindicais e líderes empresariais foram submetidos a um survey e depois a entrevistas em profundidade. Para os interesses desta discussão, concluiu-se que para estas frações os principais problemas brasileiros são de natureza social, entre eles o baixo nível educacional da população, a pobreza e a desigualdade. Para dar oportunidade de maior conhecimento sobre este público, perguntou-se quais as estratégias para sanar estas mazelas. Segundo os pesquisados deveriam ser prioritárias melhores políticas públicas no campo da educação. Para eles esta responsabilidade estaria nas mãos dos governantes pois seria um caminho para garantir oportunidades de mobilidade social.

O artigo de Scalon, de 2007, portanto sete anos depois do de Reis, também se baseando em um survey internacional, ${ }^{10}$ ocupa-se de observar as semelhanças e diferenças de opiniões sobre a desigualdade entre as elites e o povo. Aqui a pesquisa considerou elites como os $10 \%$ mais ricos do país. A intenção dos pesquisadores era preencher a lacuna de informações sobre aspectos subjetivos das desigualdades, valores e percepções vinculados à ideia de igualdade e justiça no Brasil e no mundo. De forma sintética, entre as várias conclusões apontadas na investigação, a que mais interessa é que tanto as elites como o povo julgam que os encargos sociais devem estar nas mãos dos governos. Poucos foram aqueles pesquisados que chamaram para si a responsabilidade de superar as desigualdades. Perguntados sobre os maiores problemas nacionais, as elites chamaram atenção para a corrupção e o povo mostrou preocupação com o desemprego e a pobreza. 
Em 2015, oito anos após a publicação de Scalon, Silva e López, publicam um artigo na mesma direção interessados em identificar as diferentes categorias - econômicas, culturais, políticas e morais - utilizadas pelas elites para se distinguirem ou se aproximarem do povo brasileiro, em especial dos pobres. Baseou-se em um survey com 238 sujeitos, entre parlamentares, burocratas e empresários. A noção de elite utilizada na pesquisa apoia-se na seleção dos principais postos e cargos de lideranças em instituições poderosas. Vale destacar que os dados da investigação concluíram que a pobreza é um mal gerado pelas estruturas sociais e não consequência de uma ação individual. Para os interesses desta discussão destaca-se que a má conduta do Estado ou uma ausência de vontade política são os comentários mais genéricos como explicações para as desigualdades.

Seria preciso afirmar, em um ensaio aproximativo, que os resultados de nossa consulta se assemelham aos já coletados nas investigações acima mencionadas. Uma das seções de nosso questionário perguntava: quais as principais razões para as desigualdades sociais no país?; quais os principais objetivos a serem alcançados?; quais políticas prioritárias ao combate à desigualdade?; cite explicações sobre o fracasso das políticas sociais. Mais a frente perguntou-se quais os desafios das camadas populares, camadas médias e camadas de elite no Brasil. Embora encontremos respostas distintas na população pesquisada por nós, tal como um caleidoscópio em função do setor da economia a que pertencem ou o tipo de pertencimento às elites, é um consenso a demanda por mais Educação. Seja como o principal problema nacional seja como desafio de todas as camadas sociais, a Educação surge como a grande conquista a ser alcançada.

Embora sem pretensão representativa reitera-se que existe uma tomada de posição nas elites de hoje, tal como verificado nas pesquisas anteriores, de que o maior problema da iniquidade social brasileira se assenta nas diferenças de Educação, na má gestão do Estado e na corrupção. Contudo, tudo leva a crer que existiria um equívoco nas respostas de todas as pesquisas acima, inclusive nesta investigação. Ou seja, há um consenso de que os problemas de nossas desigualdades se encontram em uma herança histórica de ausência de políticas prioritárias no combate às injustiças entre elas as políticas educacionais de caráter mais popular (REIS, 2000; SCALON, 2007). Tanto as elites como as camadas populares atribuem a um outro a competência para ações de justiça econômica, tributária, enfim, social (SILVA; LÓPEZ, 2015). Além disso, em nossa pesquisa, é geral a opinião de que se deve diminuir o tamanho do Estado, mas aumentar os gastos sociais. Garantir o crescimento econômico é também uma orientação. Mas como? O clientelismo, a 
baixa governabilidade e as desigualdades educacionais, em sendo estruturais se apresentariam, portanto, como obstáculos. Mas como reagir a eles?

\section{Os sentidos da educação enquanto socialização}

Todavia, nesta seção, valeria ressaltar que os sentidos apresentados sobre a educação são de variado espectro nos sujeitos de nossa investigação. Para alguns, a Educação se refere a um conjunto de elementos de ordem estrutural e instrucional, como escolas bem equipadas, sistemas de ensino definidos em planos nacionais, motivação de professores, alunos em condições de aproveitar os conteúdos através de ações de ordem comunitária e de políticas públicas. Para outros, Educação significa um ethos moral, emocional e ético, um pensamento prospectivo, uma ambiência familiar que promoveria ações e orientações para a disciplina no trabalho. Embora estes aspectos possam ser convergentes e complementares, eles não são iguais.

O primeiro entendimento envolve a Educação como uma política pública, como um processo de longo prazo promovido por ações planejadas tendo em seu bojo a intenção de fundar bases individuais e sociais sólidas de cultura. Um espaço de construção de habitus escolares, que segundo a visão bourdieusiana, teria intersecções com oportunidades econômicas republicanas e democráticas, enfim históricas e culturais. Mais do que isso. Criar-se-ia subjetividades que auxiliaria a vencer um mal-estar relativo a uma inferioridade tantas vezes recorrente nos cotidianos escolares, uma autoestima fundada na crença de que superariam as dificuldades.

A segunda percepção sobre a ação educativa não tem um escopo tão aprofundado. Desvelando certo pensamento classista, a educação segundo frações das elites teria a dificuldade de se fazer valer em função de idiossincrasias das camadas populares. Ou seja, a necessidade relativa à sobrevivência impediria um envolvimento familiar com um planejamento pedagógico. A inexistência do ajuste de um habitus para o trabalho, a disciplina, a ausência de um pensamento prospectivo seriam os entraves para uma população que sempre lutou pela sobrevivência, pelo aqui e o agora. Percebe-se certo conformismo nas interpretações o que impediria soluções fáceis na área. Políticas afirmativas ou políticas distributivas apenas reforçariam um tipo de conduta paternalista, uma cidadania concedida nas palavras de Sales (1994). Para muitos a situação de pobreza se perpetuará caso não se ofereça oportunidades de emprego e aumento da riqueza através da produção empresarial. Mas o equívoco aqui retorna. Como garantir o crescimento de riqueza e empregabilidade se não garantirmos as oportunidades educacionais, com políticas 
públicas planejadas, a nível municipal, estadual e federal para os grupos populares? Sabe-se que as leis para investimentos em educação pública tramitaram anos no Congresso Nacional, entre os anos 1960 a 2020. Sem nos alongar, hoje vê-se um debate acerca do $\mathrm{FUNDEB}^{11}$, que correu o risco de ser eliminado no governo do Presidente Jair Bolsonaro.

Contudo, é preciso ressaltar que os tipos de educação lembrados pelas elites não consideram o caráter temporal e relacional dos processos educativos (BOURDIEU, [1979]2007; LAHIRE, 2015). Educar e ou socializar implica em um conjunto de condições favoráveis que de maneira homeopática e inconsciente permitem que indivíduos incorporem disposições culturais estruturadas nas mentes. Mas para serem estruturantes nas formas de ser agir e pensar é necessário que haja uma correspondência entre as estruturas mentais e as estruturas sociais e objetivas. Isto é, é necessário criar condições de socialização para que resultados satisfatórios sejam garantidos. Aspectos institucionais (instrucionais e estruturais) como aqueles aqui lembrados e aspectos individuais (emocionais e individuais) devem estar dispostos em sintonia a fim de que os esforços de ambos os lados se retroalimentem e garantam disposições para o agir. Essa não parece ser uma realidade brasileira.

Ademais, a noção de socialização é um operador analítico que dá conta da produção, difusão e reprodução dos grupos e sujeitos, permitindo observar a gênese das formas de compreender o mundo, os habitus individuais e grupais. A noção de socialização também aborda as relações indissociáveis entre indivíduo e estrutura social, aproximando-se dos processos de individualização e construção identitária. Informando sobre a constituição da estrutura social, a noção permite, ainda, desvelar os mecanismos de resistência e disputa entre interesses sociais, suas dinâmicas internas e/ou possíveis transformações. Desta feita, trata-se do entendimento da noção de socialização em uma perspectiva dialógica e multidimensional (SETTON; BOZZETO, 2020).

\section{Uma intuição}

No decorrer das análises intuições ou hipóteses de pesquisa foram se construindo ao longo das entrevistas. Ou seja, haveria uma diferença relevante nas respostas dos sujeitos a partir do tipo de pertencimento às elites? Teríamos diferentes opiniões segundo o setor econômico a que pertencem? Começaremos pelas diferenças de respostas entre os sujeitos a partir do tipo de pertencimento às elites. 


\section{Sobre as elites}

Observou-se que os pesquisados que pertencem às frações de elite há três gerações possuem uma forma específica de ver seu próprio grupo. Para eles, elite significa um agrupamento seleto pois se destaca pela ética, pelo exemplo, pela possibilidade de doar-se devido a um conhecimento notável. Desenvolvem argumentos que lembram a teoria das elites ou do elitismo, entre seus maiores teóricos Vilfredo Pareto $(1848-1923)^{12}$. Uma forma singular de legitimar uma posição social a partir de uma subjetividade derivada da superioridade de seu destino e ação emanada de condições de socialização favoráveis. Eles, sim, esta elite, deveria trabalhar para uma nação, dedicando-se e participando da condução política e econômica de todo o país.

Por outro lado, as frações das elites que pertencem a ela há duas gerações, declaram certa positividade da posição do grupo, contudo não tão intensa como a que se acaba de comentar. São mais críticos pois creem que ela deveria ter o dever de conduzir a política, construir um projeto de nação, administrar a res-pública com sabedoria. Para ambas frações, as elites governamentais atuais e a dos últimos anos de nossa história, aqui incluindo os governos do PT, são corruptas. Elas não são elites. São despreparadas e incapazes de levar o país para uma modernidade sociocultural que se anuncia nos negócios do século XXI. Elas deveriam sair da bolha na qual se encontram e precisariam se preocupar com a organização dos interesses de todas as classes. Para estas frações o Brasil não está sendo induzido a participar dos desafios de uma sociedade global. Verifica-se aqui uma cobrança a nível de uma melhor organização e planejamento da parte dos governantes. Por ora, segundo eles, temos apenas um desgoverno, a falta de espaço e ambiência para uma governabilidade benéfica para o futuro de todos os brasileiros. Cumpre ressaltar que alguns deles, na maioria mulheres, se ocupam de atividades filantrópicas, de grande vulto, todas voltadas para a área social da educação e arte. Vale lembrar

ainda que a positividade das elites desta fração é marcada por trajetórias de vida em que imperativos da gestão são mais salientes. Ou seja, sentem-se responsáveis pela vinda de tecnologias para o país. Possuem experiências socializadoras adquiridas em viagens, estudos, em seus espaços de trabalho o que lhes garante, por certo, um sentimento de distinção em relação aos outros menos privilegiados (BOURDIEU, [1979]2007).

As frações intelectuais são as mais críticas entre os grupos. São aquelas que repercutem, quase na totalidade, que as elites são inconsequentes e inconscientes ao optar pela prática da corrupção e do clientelismo. Seriam eles, os governan- 
tes, responsáveis pela situação de desigualdade social no Brasil. Não se mobilizando, não se sentindo afetados pela pobreza e separação abissal entre as classes fecham-se em seus interesses, sentindo-se alheios à situação econômica e cultural dos mais vulneráveis. Não possuiriam consciência de um coletivo ou motivações solidárias com os mais fracos. Uma minoria neste grupo, e novamente aqui as mulheres se destacam, ocupa-se de atividades filantrópicas de expressão variada e, novamente, no campo da educação e das artes. Tudo leva a crer, que as experiências de socialização deste grupo lhes garantiram um ambiente reflexivo. Leituras diversas, escolas de ponta, relações de amizade e de matrimônio permitiram o desenvolvimento de disposições de cultura capazes de ampliar horizontes e de um pensamento crítico menos endógeno.

Os sujeitos que participam do quarto grupo, ou seja, aqueles que alçaram postos de comando e poder em função de sua escolarização cobram dos governos, a elite, uma vontade política mais expressiva, uma atuação igualmente eficiente dos serviços públicos e ao mesmo tempo com gastos sociais de maior monta. Para eles as elites são compostas pelos governantes corruptos, clientelistas e são expoentes exemplares do jeitinho brasileiro. Executam e planejam mal as políticas públicas prioritárias básicas como educação e saúde. É interessante notar que este grupo é marcado por difíceis condições de socialização tanto nos espaços familiares como escolares. Nem sempre estudando nas melhores escolas, tiveram que se esforçar e tecer relações interessadas para conquistarem posições de destaque, sendo aqueles que mais se privaram de privilégios de nascença.

\section{Sobre as camadas populares}

Sobre a percepção das elites acerca das camadas populares observa-se ainda variações. Entre os sujeitos há mais tempo nas elites, há três e há duas gerações, verifica-se um olhar positivo, contudo marcado por um entendimento condescendente. Ou seja, os setores populares são, segundo eles, trabalhadores, bem-intencionados, mas mal preparados. Parece que enxergam os menos privilegiados marcados por uma ordem fatalista, um círculo vicioso de mal preparo na educação, nos dois sentidos acima elencados. Ou seja, o aspecto instrucional e emocional. Vulneráveis por não terem acesso ao que a sociedade capitalista pode oferecer em termos de políticas públicas, precisariam se organizar, ter oportunidades de expressão de suas demandas para poderem disputar o poder com as elites. Aqui a solução se encontra na mão das próprias camadas populares. Elas deveriam saber aproveitar 
as oportunidades. Se a solução não vem dos setores governistas ou da própria elite, as camadas populares contariam apenas com elas mesmas.

As frações intelectualizadas e mais escolarizadas, o terceiro e quarto agrupamento, respectivamente, partilham de opiniões semelhantes acerca das camadas populares. Isto é, destaca-se o medo de políticas públicas populistas pois o comodismo poderia ser maléfico. Políticas afirmativas como Bolsa Família e cotas, por exemplo, seriam ações fronteiriças para a acomodação do povo pois a elas se somariam um despreparo moral para o trabalho. O esforço pessoal, a dedicação aos estudos, a abdicação de prazeres, a abdicação de outras tarefas como a maternidade, a renúncia aos cuidados consigo mesmo deveriam vir em primeiro plano. Não adiantaria ter estudos, conhecimento e ou diploma. Para fazer a diferença seria necessário dar o melhor de si. Observa-se aqui uma leitura individualista, meritocrática e moralista do sucesso de cada um abstraindo-se completamente de um quadro estrutural marcado por desigualdades históricas. Um contrassenso de pensamento que leva novamente a um certo fatalismo (SETTON; MARTUCCELLI, 2015).

Contudo, eles mesmos creem que seria preciso maior eficiência dos serviços públicos e maiores gastos no social. São adeptos também de uma maior distribuição de renda como se olhassem as desigualdades econômicas como os maiores gargalos de oportunidades democráticas de saúde e educação. São os que mais recriminam a corrupção e o clientelismo em crítica aos governantes como dito.

\section{Sobre as camadas médias}

No que se refere às camadas médias, os dois primeiros agrupamentos (há três e duas gerações nas elites) desenvolvem uma leitura de boa vizinhança. Em outras palavras, foi comum a interpretação de que as camadas médias estão espremidas entre os dois agrupamentos sociais acima e abaixo delas. Teriam sofrido com as últimas políticas econômicas, perdendo estabilidade e confiança em um futuro melhor e, portanto, são as camadas mais sofridas. Perderam espaço de mobilidade, necessitam de uma educação mais especializada, gastam com educação e saúde e possuem pouco espaço de manobra para melhorarem. Estes dois agrupamentos nada dizem respeito sobre uma maior organização política por parte das camadas médias. Contudo, elas deveriam também desenvolver maior civilidade, modos em espaços públicos bem como deveriam estar mais ambientadas com a produção econômica moderna, novas tecnologias, conhecimento de línguas e cursos no exterior. Pesquisas na área sociologia da educação vem demonstrando exatamente estas 
estratégias de conquistas e segurança por parte das camadas médias com mais investimentos em MBA fora e dentro do Brasil ou mesmo mais investimentos em escolas prestigiadas e bilíngues (BRANDÃO; PAES DE CARVALHO, 2011; ALMEIDA; NOGUEIRA, 2003; NOGUEIRA, 2014).

Para os setores intelectualizados e aqueles que precisaram de uma longa escolarização, para poderem dividir posições com frações da elite poder-se-ia fazer algumas aproximações. Segundo os pesquisados as camadas médias são algozes de si mesmas. Construindo castelos de consumo exagerado, gastos acima de suas possibilidades, vivem reféns de um estilo de vida que não pertence realmente a elas. Sonhando se assemelhar às camadas mais abastadas, creem poder desfrutar das benesses do capitalismo de consumo. Não possuem a cultura da poupança. Defrontando-se com saúde e educação de má qualidade seus maiores desafios seriam sobreviver, obter empregabilidade e maior acesso a cultura. Neste sentido, as elites não depositam o fiel da balança de um projeto social nos ombros das camadas médias. Elas deveriam estar mais atentas a si mesmas e às dificuldades de um país que aceleradamente desponta entre os mais desiguais no mundo.

Em síntese, existiria uma pequena convergência de opiniões sobre os desafios das camadas de elite, camadas médias e populares nas frações das elites. O tipo de pertencimento aos grupos privilegiados parece ter sido responsável por esta variação. Mais tempo subjetivados com o modus vivendi das camadas mais elevadas poucos são aqueles que são críticos a si mesmos (SETTON; MARTUCCELI, 2015). Todavia, os setores mais intelectualizados e altamente escolarizados parecem se desgarrar desta subjetividade, sendo capazes de cobrar das elites maior envolvimento nas políticas de mudanças das prioridades sociais.

Veremos agora se estes sujeitos pesquisados também diferem segundo o setor econômico a que pertencem.

\section{Uma segunda intuição}

A classificação dos sujeitos pelo setor de atividade a que pertencem derivou de uma intuição não original. Segundo a bibliografia das teorias da socialização (BOURDIEU, [1979]2007; ELIAS, 1999), a posição social e a formação necessária para o desempenho de atividades em domínios econômicos distintos levam a tomadas de posição diferenciadas. Nesse sentido, buscou-se observar essas diferenças acerca das questões sobre desigualdade e desafios das camadas sociais. 
Vale iniciar a explanação considerando que os sujeitos que compõe os vários setores não são coincidentes com o tipo de pertencimento às elites. Isto é, a composição destes grupos é bastante heterogênea ${ }^{13}$.

Lembramos que é unânime entre os investigados, de todos os setores, uma crítica ao governo. As entrevistas começaram a ser realizadas em 2018, ano em que o debate sobre corrupção e as eleições presidencial, governamentais e do legislativo ativaram um debate acirrado e violento entre as partes envolvidas. Nas questões relativas às razões da desigualdade social no Brasil e as dificuldades de superá-las, todos, sem exceção, culpam a corrupção, a má governabilidade, a baixa eficiência dos serviços públicos, a transformação das prioridades sociais em carreirismos e clientelismo. Desigualdade para todos os setores tem o sentido de baixo nível educacional e deficientes serviços de saúde. É uma constante, mas não de forma generalizada, a cobrança por uma postura mais ativa das elites. Elas poderiam conduzir melhor o processo político com cobranças no ordenamento administrativo. Muitos advogam a diminuição do Estado, mas ao mesmo tempo querem aumentar os gastos sociais. Como visto acima, observa-se uma inconsistência nas respostas. Cobram de si mesmos, as elites, uma atuação mais direta, mas parecem não obedecer suas premissas. Lembram que o mal planejamento e execução, o clientelismo e a corrupção são as causas do fracasso das políticas sociais, mas pouco fazem para mudar. Relatam pouco envolvimento ainda que digam que as elites precisariam estar mais implicadas. Apenas um sujeito demonstrou ativa atuação na promoção de um novo partido político. Como foi dito, uma gama variada de ONGs de grande vulto na área da educação e das artes e outros poucos trabalhos filantrópicos de pequena monta fazem parte das atividades de alguns. Tudo leva a crer que estamos diante de um círculo vicioso que engessa uma mudança vinda por parte deles, pela classe política ou pelas camadas populares, já que a filantropia, ainda que humanitária, não resolve as questões estruturais da desigualdade. Cada grupo preso a interesses relativos à sua reprodução mergulhados em um sentimento de distanciamento cultural.

Antes de dar encaminhamento às questões expostas acima, valeria comentar que existiria uma recorrência nos dados relativos à filantropia. Observou-se que $o$ setor do agronegócio apresentou o maior número de sujeitos envolvidos com esta atividade. De 5 representantes, 3 dedicam-se quase exclusivamente a esta prática, todas elas de grande monta e um dedica-se esporadicamente a ações do tipo. Por outro lado, os setores que menos se envolvem com a atividade da filantropia são os dos altos executivos, profissionais liberais e celebridades intelectuais. No setor 
da indústria tem-se a presença de 2 sujeitos envolvidos em ações beneficentes de grande vulto e entre os políticos tem-se um representante de organizações do terceiro setor, internacionalmente reconhecida, pelo envolvimento de sua diretoria; no setor das finanças, 2 deles se envolvem em formação de políticos e artistas, com dedicação de dinheiro e tempo. Em síntese, de todos os sujeitos entrevistados 9 deles se dedicam quase exclusivamente a atividades de filantropia e 9 consagram seu tempo esporadicamente, assim que solicitados, para este fim. Por último, se classificarmos os indivíduos por tipo de pertencimento às elites, com fins caritativos na esfera da educação e arte, verifica-se certa pulverização. Quatro deles estão entre os que alçaram postos de destaque pela escolarização, 3 estão há três gerações e 2 vieram de famílias intelectualizadas.

Sem dúvida, a segunda intuição de pesquisa não se realizou de forma suficiente. Tudo levava a crer que haveria distinções acentuadas nas respostas dos diferentes setores. Todavia, isto não se confirmou inteiramente. O que se observou foi uma certa generalidade nas respostas que podem indicar dificuldades no tipo de questões postas. Como não corroborar os problemas da desigualdade? Como justificar as desigualdades educacionais e de saúde? Por ser um assunto consensual presente nas mídias, cotidianamente, seria esperado um posicionamento crítico acerca deles. Entretanto, o que desperta atenção é a cobrança às políticas governamentais, seu modus operandi, e a exigência por uma maior atitude do grupo a que pertencem. É possível afirmar que a amostra utilizada não refletiria parte do empresariado que apoiou o governo conservador e neoliberal que ganhou as eleições em 2018? Uma outra hipótese, os entrevistados teriam feito cobranças retóricas e críticas às elites pois estariam diante de uma entrevistadora socióloga e professora da USP?

\section{Em busca de uma conclusão}

O objetivo deste artigo foi apresentar informações preliminares acerca da pesquisa intitulada Pensamento e práticas culturais da elite paulistana. A intenção foi problematizar e circunstanciar questões de ordem metodológica e teórica observadas no decorrer do trabalho de investigação. Para desenvolver o argumento foi necessário dialogar com iniciativas de estudos acerca das elites. Se de um lado, o campo da educação já se dedicou aos processos de suas escolarizações, por outro, pouco se sabe sobre suas representações acerca da realidade social brasileira. 
O presente estudo colabora para uma agenda de pesquisa em que se tem como foco a oportunidade de conhecimento sobre este grupo de difícil acesso. Julga-se que a maior contribuição científica e social da discussão seja a produção de informações acerca das frações das elites, suas formas de socializar homens e mulheres, em quatro gerações, suas práticas de cultura e representações sociais, bem como apreender as formas como interpretam a atual realidade nacional. Este artigo deu ênfase a apenas às representações sobre desigualdade e a visão sobre os desafios das camadas sociais ${ }^{14}$.

Esta discussão se insere ainda no escopo de preocupações sobre socialização ao se propor desvelar as formas de ser, agir e pensar dos grupos dominantes que possuem o poder de conduzir políticas de equidade social. Segundo o relatório da OXFAM Brasil/DATAFOLHA (2019), desde 2014, tem crescido o número de pobres no Brasil. $86 \%$ da população acredita que o progresso do país está condicionado à redução de desigualdades entre ricos e pobres. $84 \%$ julgam que é obrigação dos governos diminuir a diferença entre os muitos ricos e muitos pobres e, a melhor forma para sanar este prejuízo seria a aumentar a tributação.

Do material apresentado neste artigo, concluiu-se, pois, que as experiências socializadoras das elites marcaram posicionamentos diferenciados. Um achado de relevo pois deriva de condicionamentos vividos em espaços e tempos de instâncias da socialização distintos. Todavia, cumpre ressaltar que tudo leva a crer que existiria uma falta de entendimento acerca da Educação enquanto Socialização no grupo investigado. Ou seja, uma Educação em um sentido mais largo. Trata-se da incompreensão dos processos educativos e ou socializadores relativos a um povo que demanda tempo, esforço, dedicação e sobretudo dinheiro, impedindo ações mais incisivas e prospectivas. Ações benemerentes resultam em produtos localizados. Talvez uma resposta inicial para as inconsistências das falas dos entrevistados se encontre aqui. Ou seja, cobram viciosamente a conduta governamental e a deles mesmos, mas pouco compreendem a temporalidade longeva de esforços socializadores e educativos necessários. Por fim, tendo como base a obra de Pierre Bourdieu, o artigo se insere em uma vertente das teorias do poder e da dominação simbólica, largamente estudadas pelo autor. Aqui evidenciou-se um sentimento de superioridade destas frações, uma percepção distintiva entre eles e os outros o que as impedem de compreender os processos vividos como estruturais e históricos. Por certo, a teoria sobre habitus e práticas de cultura permite a identificação da gênese desses processos desiguais, ou seja, os processos socializadores que os forjaram. 
Por fim, verificou-se que o tecido social brasileiro vivencia climas de consensos, insatisfações e distanciamento entre os grupos, mas não consegue ultrapassar uma zona em que se saia da inércia e avance em práticas socializadoras de cultura mais contundentes e duradouras. Ou seja, praticas institucionais, instrucionais, morais e emocionais em um todo educativo mais complexo. Em outras palavras, as representações das frações das elites acerca da desigualdade social descortinaram um ambiente que se repete desde os primeiros estudos sobre o assunto. Talvez a inércia dos procedimentos em busca de uma solução derive de uma incompreensão da natureza cultural, temporal e histórica dos processos educativos e ou socializadores. Mais estudos na área podem vir a colaborar. Ainda é tempo.

\section{Notas}

1 "Este ponto de vista deveria ser também objeto de uma reflexão coletiva ao interrogar a capacidade que um profissional tem ao produzir um ponto de vista sobre o funcionamento das elites que não seja tributário nem de uma revanche de classe, nem de uma forma de admiração, nem mesmo enfim de um tropismo escolástico" (LAURENS, 2007).

2 Trata-se de uma pesquisa realizada desde 2017, no GPS - Práticas de Socialização, grupo de Pesquisa da Faculdade de Educação da USP, sob minha coordenação.

3 Este artigo é o terceiro de uma série de outros que estão sendo escritos e já foram publicados acerca da pesquisa em tela. Já foram publicados Setton e Bozzeto (2020) e Setton (2020).

4 Algumas hipóteses desta investigação a) nossas elites, de forma genérica, são voltadas para o próprio interesse. Ou seja, trabalham com a lógica gerencial/empresarial e a compreensão política que mobiliza suas ações não chega a tocar as questões sobre desigualdade social e/ou direitos sociais equânimes. Contudo, todas essas frações pensariam igual? Ambas as gerações, homens e mulheres, pensariam de forma semelhante (SCALON, 2007)? b) nossas elites se pensam diferentes e superiores dos outros segmentos sociais. Vivendo em espaços circunscritos ao grupo de pares, longe das exigências materiais, se subjetivam e constroem uma percepção de si e de grupo como superiores. O entendimento é que seriam merecedores do que conquistaram. Esforço, dedicação em termos individuais parecem aspectos que legitimam esta superioridade (SETTON; MARTUCCELLI, 2015); c) as elites não julgam as trajetórias sociais em termos estruturais. A dimensão societária, a dimensão da concentração de renda e oportunidades como responsáveis pela perpetuação das desigualdades sociais parecem não ter eco em seus entendimentos e atitudes; d) as distintas frações da elite possuem trajetórias diferentes, não possuem as mesmas práticas de cultura, embora possuam os mesmos valores e estratégias de manutenção da dominação. Em função do tipo de disposição cultural acumulada em espaços de socialização profissional diversos seria esperado tal dessemelhança; e) nossas elites estão voltadas para o exterior. O mundo europeu e sobretudo norte-americano seriam os modelos a seguir. Uma certa limitação do pensamento em que não se vê a condição histórica das mazelas do Brasil e a necessidade de um esforço conjunto para a sua superação. Tal perspectiva seria generalizada? Todas as frações teriam esta mesma compreensão? Tal complexo de vira-lata impediria uma crença maior nas nossas instituições sociais (SOUZA, 2015)?

5 Entende-se elite como aqueles que ocupam o topo de organizações e movimentos poderosos, podendo influenciar a vida política, econômica, social e cultural. Mais detalhes sobre a discussão ver Setton (2020).

6 Por exemplo, a qual grupo social se sentiam pertencer.

7 Um artigo está sendo escrito sobre as questões geracionais e de gênero.

8 Par objectivation participante j'entends objectivation du sujet de objectivation, objectivation du sujet analysant bref du chercheur lui-même celle qui consiste à observer observant à observer observateur dans son travail observation ou de transcription de ses observations dans et par un retour sur expérience du terrain (BOURDIEU, 2003). 
9 Pesquisa realizada no Instituto Universitário de Pesquisa do Rio de Janeiro, intitulada Elites estratégicas e consolidação democrática, no período de 1993 a 1995.

${ }^{10}$ Pesquisa que fez parte de investigações do Internacional Social Survey (ISSP), programa de colaboração internacional acerca de estudos na área da Ciências Sociais, a partir de análises comparativas, em 2000.

${ }^{11}$ Fundo de Manutenção e Desenvolvimento do Ensino Fundamental e de Valorização do Magistério é um conjunto de fundos contábeis formado por recursos dos três níveis da administração pública do Brasil para promover o financiamento da educação básica pública. A maior inovação do FUNDEF consiste na mudança da estrutura de financiamento do Ensino Fundamental no País ( $1^{\mathrm{a}}$ a $8^{\mathrm{a}}$ séries do antigo $1^{\mathrm{o}}$ grau , ao subvincular a esse nível de ensino uma parcela dos recursos constitucionalmente destinados à Educação. A Constituição de 1988 vincula $25 \%$ das receitas dos Estados e Municípios à Educação. Com a Emenda Constitucional no 14/96, 60\% desses recursos (o que representa $15 \%$ da arrecadação global de Estados e Municípios) ficam reservados ao Ensino Fundamental. Além disso, introduz novos critérios de distribuição e utilização de $15 \%$ dos principais impostos de Estados e Municípios, promovendo a sua partilha de recursos entre o Governo Estadual e seus municípios, de acordo com o número de alunos atendidos em cada rede de ensino. Disponível em: http://mecsrv04.mec.gov.br/sef/fundef/funf.shtm.

${ }_{12}$ Trata-se de uma categoria mobilizada para a observação de todos os grupos dispostos na sociedade. A premissa dessa ideia é que, em qualquer ramo da atividade humana, alguns homens são melhores do que outros e alcançam maior destaque no desempenho de seus ofícios. O que define as elites, assim, é um princípio de eficiência, e não um critério moral (PARETO, 1989).

${ }^{13}$ Por exemplo, no setor do agronegócio, com 5 sujeitos, 2 deles alçaram postos no grupo das elites pela escolarização, quase todos herdeiros de propriedades em função de laços matrimoniais ou filiais. Entre os altos executivos, todos dependeram de uma escolarização qualificada em expertises que se destacam no mundo dos negócios internacionais. No grupo das celebridades intelectuais, tem-se 3 sujeitos que fizeram carreira pela escolarização em instituições estrangeiras, 1 deles herdeiro de um lar já intelectualizado e o último pertencente há três gerações nas elites. Entre os pesquisados no setor do comércio, todos vieram de lares de imigrantes libaneses, espanhóis e alemães. Ressalta-se que 2 sujeitos estão há duas gerações nas elites e um há três gerações. Dois dependeram da escolarização e 1 veio de meios intelectualizados. No setor de comunicação, 4 são de famílias estrangeiras, sendo que todos vieram de lares já intelectualizados. Ainda neste setor, um sujeito pertence às elites há três gerações e um único pela escolarização. No grupo das finanças, 2 herdeiros de um capital cultural distintivo, 2 pela escolarização e um há três gerações nas elites. Na indústria, 4 são imigrantes, espanhóis, italianos e da Europa Oriental. Dois estão nas elites há três gerações, 3 pela escolarização e um pertencente ao grupo de famílias intelectualizadas. Entre os políticos, 4 estão nas elites há três gerações e 2 pela escolarização. Por último, entre os profissionais liberais, 3 alçaram posições de destaque pela escolarização e 1 pelo capital cultural intelectualizado de sua família.

${ }^{14}$ Este artigo é o segundo de uma série de outros que estão sendo escritos acerca da pesquisa em tela. O primeiro deles é Setton (2020).

\section{Referências}

ALMEIDA, A. A.; NOGUEIRA, M. A. (org.). A escolarização das elites: um panorama internacional de pesquisa. Petrópolis: Vozes, 2003.

BERTHELOT, J.-M. Pour un bilan de la sociologie de l'éducation. In: COLLOQUE DE TOULOUSE, 1983. Anais [...]. Toulouse, 1983.

BOURDIEU, Pierre. Objectivation participant. Actes de La Recherche en Science Sociales, Paris, 2003.

BOURDIEU, Pierre. A distinção - crítica social do julgamento. São Paulo: EDUSP; Editora Zouq, (1979) 2007.

BRANDÃO, Z.; PAES DE CARVALHO, C. Processos de Produção das elites escolares. Educação e Sociedade, Campinas, 2011. 
GENÉ, Mariana. Sociologia política de las elites. Apuntes sobre su abordaje a través de entrevistas. Revista de Sociologia e Política, Curitiba, v. 22, n. 52, out./dez. 2014.

ELIAS, Norbert. Introdução à Sociologia. 10. ed. Lisboa: Editora 70, (1970) 1999.

KHAN, Shamus Rhaman. The sociology of elites. Annual Review of Sociology, v. 38, p. 361-377, 2012.

LAHIRE, Bernard. A fabricação social dos indivíduos: quadros, modalidades, tempos e efeitos de socialização. Educação e Pesquisa, São Paulo, v. 41, n. especial, p. 1393-1404, dez. 2015.

LAURENS, S. Pourquoi et comment poser les questions qui fachent? Reflexions sur les dilemmes récurrents que posent les entretiens avec des imposants. Génèses, Belin, n. 69, 2007.

PARETO, V. A circulação das elites. In: CRUZ, M. Braga da (org.). Teorias sociológicas. V. 1. Lisboa: Fundação Calouste Gulbenkian, 1989.

PINÇON, M.; PINÇON-CHARLOT, M. Dans les beaux quartiers. Paris : Seuil, 1989.

PINÇON, M.; PINÇON-CHARLOT, M. Sociologia da alta burguesia. Sociologias, Porto Alegre, jul./dez. 2007.

NOGUEIRA, M. A. Favorecimento econômico e excelência escolar. Revista Brasileira de Educação, Anped, Rio de Janeiro, 2014.

OXFAM BRASIL/DATAFOLHA. Nós e as desigualdades - percepções sobre desigualdades no Brasil. São Paulo, abril 2019.

REIS, Elisa. Percepções da elite sobre pobreza e desigualdade. Revista Brasileira de Ciências Sociais, Anpocs, 2000.

SALES, Teresa. Raízes da desigualdade social na cultura política brasileira. Revista Brasileira de Ciências Sociais, ano 9, n. 25, jun. 1994.

SCALON, Celi. Justiça como igualdade? A percepção da elite e do povo brasileiro. Sociologias, Porto Alegre, 2007.

SETTON, M. G. J. Estudos sobre as elites: uma leitura da produção em periódicos entre 19982017. Revista Pro-Posições, Campinas, 2020.

SETTON, M. G. J.; BOZZETTO, A. Notas provisórias sobre a noção de socialização. Uma leitura em periódicos da educação (1998-2018). Educação e Sociedade, Campinas, 2020.

SETTON, M. G. J. ; MARTUCCELLI, D. Dossiê - A escola: entre o reconhecimento, o mérito e excelência. Educação e Pesquisa, FE-USP, São Paulo, 2015.

SILVA, M. G.; LÓPEZ, M. Brazilian people in the eyes of elites: repertoires and symbolic boundaries of inequality. Sociologia e Antropologia, Rio de Janeiro, 2015.

SOUZA, Jessé. A tolice da inteligência brasileira: ou como o país se deixa manipular pela elite. São Paulo: Leya, 2015.

THERBORN, G. Globalização e desigualdade: questões de conceituação e esclarecimento. Sociologias, Porto Alegre, 2001. 